\title{
Dietary flavonoids against various breast cancer subtypes: a molecular docking study
}

\author{
Wahyu Widowati ${ }^{\mathrm{a}, *}$, Diana Krisanti Jasaputra ${ }^{\mathrm{a}}$, Yusuf Heriady ${ }^{\mathrm{b}}$, Ahmad Faried $^{\mathrm{c}}$, Rizal Rizal ${ }^{\mathrm{d}}$, \\ Wahyu Setia Widodo $^{\mathrm{d}}$, Satrio Haryo Benowo Wibowo ${ }^{\mathrm{d}}$, Hanna Sari W Kusuma ${ }^{\mathrm{d}}$, Ermi Girsang ${ }^{\mathrm{e}}$, \\ I Nyoman Ehrich Lister ${ }^{\mathrm{e}}$ \\ ${ }^{a}$ Faculty of Medicine, Maranatha Christian University, Bandung 40164, West Java, Indonesia \\ b Faculty of Medicine, Bandung Islamic University, Bandung 40116, West Java, Indonesia \\ c Department of Neurosurgery and Stem Cell Working Group, Faculty of Medicine, Universitas \\ Padjadjaran-Dr. Hasan Sadikin Hospital, Bandung, West Java, Indonesia \\ d Biomolecular and Biomedical Research Centre, Aretha Medika Utama, Bandung 40163, West Java, \\ Indonesia \\ e Universitas Prima Indonesia, Medan 20118, North Sumatera, Indonesia
}

*Corresponding author, e-mail: wahyu_w60@yahoo.com

Received 14 Jul 2019

Accepted 30 Oct 2019

\begin{abstract}
Breast cancer is female most frequent diagnosed cancer and the leading cause of cancer death. The consumption of dietary flavonoids is reported to cause significant breast cancer risk reduction. In vitro studies often used aglycone flavonoids rather than its conjugated form that actually present in human body. Thus its mechanism against breast cancer has not been elucidated completely. The present study aimed to investigate the possible mechanism of dietary flavonoids against breast cancer by in silico study. Conjugated flavonoids were docked to ER (estrogen receptor), HER2 (human epidermal growth factor receptor 2) and EGFR (epidermal growth factor receptor) kinase domains. The molecular docking of 22 flavonoid conjugates towards EGFR and HER2 kinase domain, and ER was successfully performed. Potential binders to proteins: epicatechin conjugates to ER $(-8.7 \mathrm{kcal} / \mathrm{mol})$, isoflavone conjugates to HER2 kinase domain $(-10.7 \mathrm{kcal} / \mathrm{mol})$, and epigallocatechin and epicatechin conjugates to EGFR kinase domain $(-9.2 \mathrm{kcal} / \mathrm{mol})$, were suggested. Supported by other studies, conjugated flavonoids may exert similar inhibitory and agonistic properties to their parent flavonoids. Taken together, the present study showed possible effects of dietary flavonoids against various breast cancer subtypes.
\end{abstract}

KEYWORDS: molecular docking simulation, diet, flavonoids, antineoplastic agents, breast neoplasms

\section{INTRODUCTION}

According to GLOBOCAN 2018 database, breast cancer is female most diagnosed cancer and the leading cause of cancer death ${ }^{1}$. Breast cancer is heterogenous disease, comprised of various subtypes observable by the presence of the predictive molecular markers. Breast cancer can be categorized into: Luminal $\mathrm{A}\left(\mathrm{ER}^{+}, \mathrm{PR}^{+/-}, \mathrm{HER}^{-}\right)$, Luminal $\mathrm{B}\left(\mathrm{ER}^{+}\right.$, $\mathrm{PR}^{+/-}, \mathrm{HER} 2^{+}$), HER2 $\left(\mathrm{ER}^{-}, \mathrm{PR}^{-}, \mathrm{HER} 2^{+}\right)$, basal like and claudin low (triple negatives) ${ }^{2}$. Each has a different prognosis and responds differently to cancer treatment. Luminal A has the best prognosis, while $\mathrm{HER}^{+}$and triple negative breast cancer (TNBC) have the poorest ${ }^{3}$. Today breast cancer endorsed to be treated with endocrine theraphy, targeted theraphy, and cytotoxic chemotheraphy ${ }^{4}$. Breast cancer with high expression of estrogen receptor
(ER) and progesterone receptor (PR) is sensitive against endocrine theraphy. ER inhibition treatment in Luminal A and B breast cancer was proven to be effective and safe ${ }^{5}$. While HER2 ${ }^{+}$breast cancer was effectively treated using targeted theraphy with trastuzumab or lapatinib ${ }^{6}$. But different from previous subtypes, triple negative breast cancer is not responded very well to hormone treatment and HER2 antibody, and often treated with systemic chemotherapy. Previous study found that epidermal growth factor receptor (EGFR) kinase inhibitor, gefitinib, was able to halt the TNBC cell outgrowth in vitro $^{7}$. Thus ER, HER2, EGFR served as important targets in breast cancer treatment. It is also possible other chemical compounds found in food may also interacts with these particular proteins. Flavonoid is the most common phytochemical compound found 
ubiquitously in human $\operatorname{diet}^{8,9}$ and has huge impact in human health. In vitro studies showed that flavonoids have wide range of biological activity antioxidant, anti-inflammatory, anti-microbial, antifungal, antiviral, and anti-cancer ${ }^{9,10}$. Consumption of flavonoids is related with less risk of cardiovascular diseases and stroke ${ }^{11,12}$. Other studies found that the intake of flavonoids improved the outcome of the gastric and lung cancer ${ }^{13,14}$. Human study on consumption of food rich in flavonoids, green tea, against breast cancer showed mixed results. Case studies has shown green tea intake was correlated with significant breast cancer risk reduction ${ }^{15-17}$, while recent prospective cohort studies showed no correlation ${ }^{18}$. Soy products were rich in isoflavone and high soy intake was modestly associated with reduced breast cancer risk ${ }^{19}$.

It is important to note that flavonoid is quickly metabolized in the body. After ingested, glycoside flavonoid found in plant materials is subjected to deglycosylation, releasing aglycone compound that readily absorbed by the intestine lining ${ }^{20}$. Once entered circulatory system, flavonoid is immediately transported to liver and undergoes extensive metabolism. Phase metabolism II transformed free aglycone onto flavonoid conjugates by adding glucuronides and sulphate moiety ${ }^{21}$. Because of this, aglycone flavonoids are rarely found in plasma. Previous in vitro studies often used aglycone flavonoids rather than its conjugated forms that present in human body. Thus its mechanism against breast cancer has not been elucidated completely, since conjugation may affect how the molecules behave. To address this, conjugated flavonoids found in plasma after ingesting food rich in flavonoid was subjected to molecular docking against ER, HER2, EGFR. The present study describes possible mechanism how the dietary flavonoids may contribute against breast cancer.

\section{MATERIALS AND METHODS}

Molecular docking towards EGFR, HER2, and ER

Conjugated flavonoids found in plasma after ingesting food rich in flavonoids as previously reported from other studies were used ${ }^{22-24}$. Structural data of conjugated flavonoids were retrieved from PubChem database (Fig. 1) (pubchem.ncbi. nlm.nih.gov). Co-crystallized structures of ER4-hydroxytamoxifen (PDB ID: 3ERT) ${ }^{25}$, HER2SYR127063 (PDB ID: 3PP0) ${ }^{26}$, and EGFR-gefitinib (PDB ID: 4WKQ) were obtained from RCSB database (rcsb.org). Crystal structure data were
Table 1 Predicted binding affinity (kcal/mol) of flavonoid conjugates and known inhibitors towards ER, HER2, and EGFR.

\begin{tabular}{lccc}
\hline \multirow{2}{*}{ Flavonoid conjugate } & \multicolumn{3}{c}{ Binding affinity } \\
\cline { 2 - 4 } & ER & HER2 & EGFR \\
\hline Gefitinib & - & - & -8.8 \\
SYR127063 & - & -11.0 & - \\
4-hydroxytamoxifen & -9.7 & - & - \\
(-)-Epicatechin-3-gallate & -8.7 & -8.5 & -8.6 \\
(-)-Epigallocatechin-3-gallate & -7.0 & -8.6 & -9.2 \\
(-)-Epigallocatechin-7-gallate & -7.4 & -8.9 & -8.0 \\
4'-Methylepicatechin-5-sulfate & -7.2 & -8.8 & -7.7 \\
4'-Methylepicatechin-7-sulfate & -7.9 & -9.6 & -7.2 \\
4'-Methyl-epigallocatechin- & -7.9 & -9.9 & -9.1 \\
$\quad$ 3'-glucuronide & & & \\
4'-Methyl-epigallocatechin- & -6.5 & -9.0 & -8.2 \\
$\quad$ 7-glucuronide & & & \\
Daidzein-4'-sulfate & -7.1 & -9.4 & -8.5 \\
Daidzein-7-sulfate & -6.6 & -9.2 & -8.4 \\
Epicatechin-3'-glucuronide & -8.5 & -9.5 & -9.1 \\
Epicatechin-3'-sulfate & -7.7 & -9.1 & -8.2 \\
Epicatechin-5-sulfate & -7.1 & -8.6 & -8.4 \\
Epicatechin-7-lucuronide & -7.5 & -9.3 & -8.3 \\
Epigallocatechin-3'-glucuronide & -7.7 & -9.7 & -9.1 \\
Epigallocatechin-7-glucuronide & -7.2 & -8.3 & -8.3 \\
Genistein-4'-O-glucuronide & -8.3 & -10.7 & -8.0 \\
Genistein-4'-sulfate & -7.3 & -9.7 & -8.3 \\
Genistein-7-O-glucuronide & -6.8 & -9.4 & -7.7 \\
Genistein-7-sulfate & -6.4 & -9.1 & -8.6 \\
Isorhamnetin-3-O-glucuronide & -7.6 & -8.3 & -8.8 \\
Quercetin-3'-glucuronide & -8.7 & -8.8 & -8.7 \\
Quercetin-3'-sulfate & -8.1 & -9.5 & -8.4 \\
\hline & & & \\
\hline
\end{tabular}

prepared by removing solvent and extracting bound ligand. AutoDock vina was used in molecular docking under default settings. The docking methodology was validated by redocking the extracted bound ligand. Chimera was used on visualization in this study. Intramolecular analysis was performed using Pose View, available at Protein Plus (proteins. plus) ${ }^{27}$.

\section{RESULTS}

\section{Molecular docking analysis}

Redocking was performed to evaluate software and docking parameters used. The root mean square deviation between docked and crystal compounds was less than $2 \AA$ except for EGFR bound ligand (gefitinib). This is due to the 6-propylmorpholino moiety of gefitinib sticking out to solvent and able to move freely ${ }^{28}$. Thus, AutoDock Vina has favourable accuracy and proceeds the docking of flavonoid- 


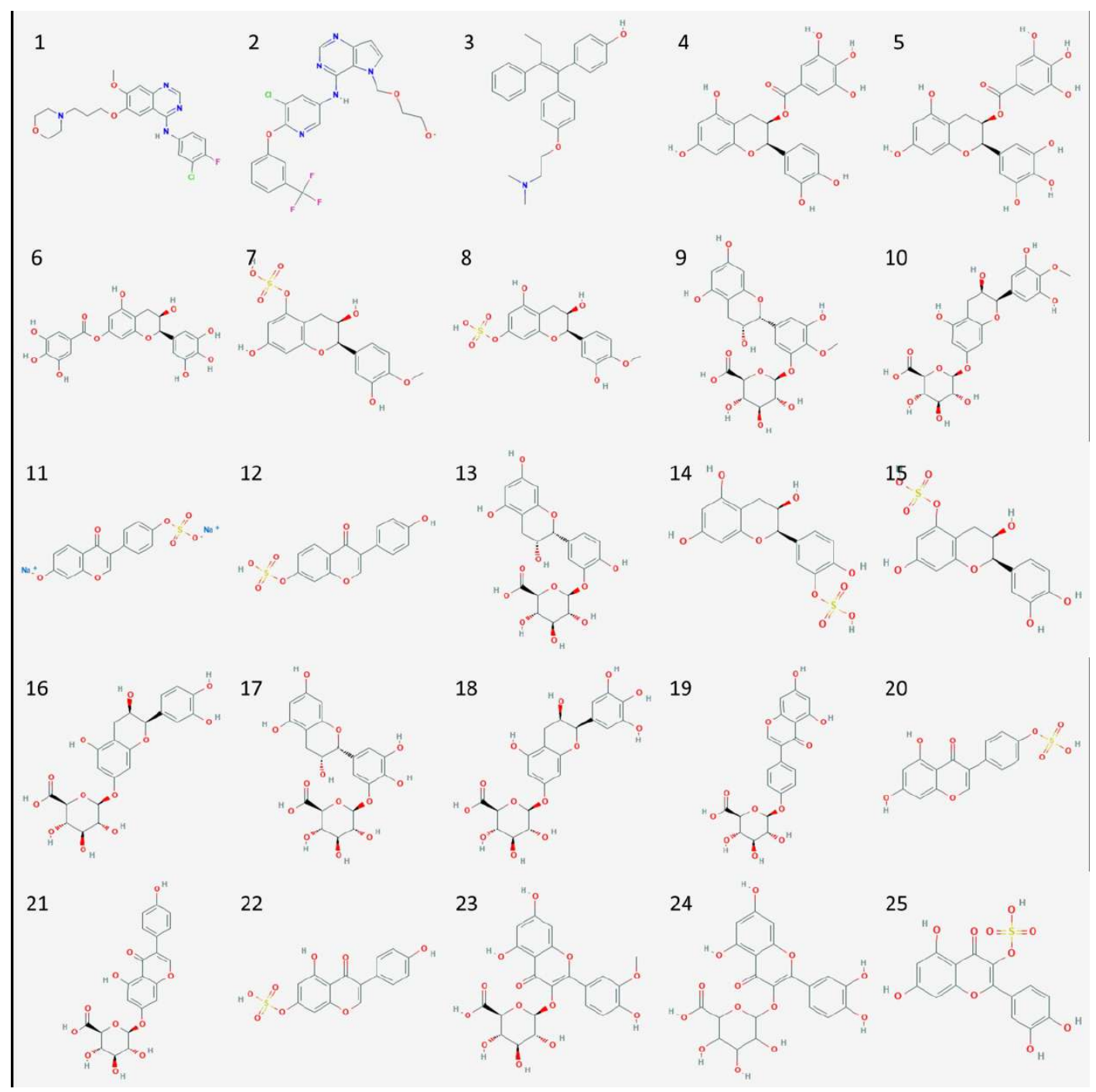

Fig. 1 The 2 dimensional structure of all studied ligands: (1) gefitinib, (2) SYR127063, (3) 4-hydroxytamoxifen, (4) (-)-epicatechin-3-gallate, (5) (-)-epigallocatechin-3-gallate, (6) (-)-epigallocatechin-7-gallate, (7) 4'methylepicatechin-5-sulfate, (8) 4'-methylepicatechin-7-sulfate, (9) 4'-methyl-epigallocatechin-3'-glucuronide, (10) 4'-methyl-epigallocatechin-7-glucuronide, (11) daidzein-4'-sulfate, (12) daidzein-7-sulfate, (13) epicatechin3'-glucuronide, (14) epicatechin-3'-sulfate, (15) epicatechin-5-sulfate, (16) epicatechin-7-glucuronide, (17) epigallocatechin-3'-glucuronide, (18) epigallocatechin-7-glucuronide, (19) genistein-4'-O-glucuronide, (20) genistein-4'-sulfate, (21) genistein-7-O-glucuronide, (22) genistein-7-sulfate, (23) isorhamnetin-3-O-glucuronide, (24) quercetin-3'-glucuronide, (25) quercetin-3'-sulfate.

conjugates. The molecular docking was performed to assess possible binding conformation of flavonoid conjugates towards receptors and possible biological actions of these compounds. The molecular docking of 22 flavonoid conjugates towards EGFR and HER2 kinase domain, and ER was successfully performed. The predicted binding affinity value of flavonoid conjugates was compared to each other and receptor bound ligand (Table 1).
In the present study, based on molecular docking, epichatehin and quercetin conjugates ((-)epicatechin-3-gallate, quercetin-3'-glucuronide, and epicatechin-3'-glucuronide) were predicted as a potential binder towards estrogen receptor. HER2 kinase domain was predicted to interact strongly towards genistein and epigallocatechin conjugates (genistein-4'-O-glucuronide, genistein4'-sulfate, epigallocatechin-3'-glucuronide, 
Table 2 Hydrogen bond formed by flavonoids conjugates and known inhibitors towards EGFR, HER2, and ER.

\begin{tabular}{|c|c|c|}
\hline Flavonoid conjugate & Receptor & Hydrogen bond \\
\hline $\begin{array}{l}\text { 4-hydroxytamoxifen } \\
\text { (-)-Epicatechin-3-gallate } \\
\text { Quercetin-3'-glucuronide }\end{array}$ & ER & $\begin{array}{l}\text { Asp394 Glu353 } \\
\text { Leu346 Thr347 Asp351 } \\
\text { Leu387 Glue419 Gly420 } \\
\text { Asp351 Glu353 }\end{array}$ \\
\hline $\begin{array}{l}\text { SYR127063 } \\
\text { Genistein-4'-O-glucuronide }\end{array}$ & HER2 & $\begin{array}{l}\text { Met801 Asp863 } \\
\text { Ser783 Thr798 }\end{array}$ \\
\hline $\begin{array}{l}\text { Gefitinib } \\
\text { (-)-Epigallocatechin-3- } \\
\text { gallate }\end{array}$ & EGFR & $\begin{array}{l}\text { Met793 } \\
\text { Glu762 Leu788 Met793 } \\
\text { Arg841 }\end{array}$ \\
\hline
\end{tabular}

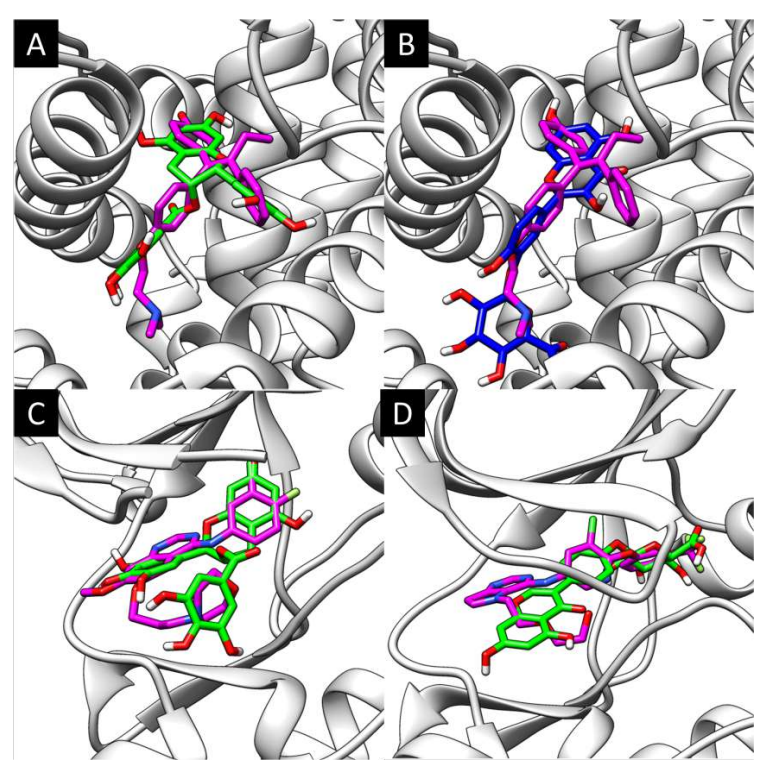

Fig. 2 Superimposed binding mode between flavonoid conjugate and known inhibitor towards ER, HER2, EGFR. (A) and (B) the binding mode of (-)-epicatechin-3gallate (green), quercetin-3'-glucuronide (blue), and 4hydroxytamoxifen towards (magenta) ER (light gray). (C) the binding mode of genistein-4'-O-glucuronide (green) and SYR127063 (magenta) towards EGFR kinase domain (light gray). (D) the binding mode of (-)-epigallocatechin-3-gallate (green) and gefitinib (magenta) towards HER2 kinase domain (light gray). The protein represented as ribbon, the compound as stick, and heteroatom represented in a different color from the carbon atom.

and 4'-methyl-epigallocatechin-3'-glucuronide) compared to other compounds. While several catechin derivatives ((-)-epigallocatechin-3gallate, 4'-methyl-epigallocatechin-3'-glucuronide, epicatechin-3'-glucuronide, and epigallocatechin3'-glucuronide) were predicted with a high affinity toward EGFR kinase domain as these compounds surpassed known inhibitor binding score.

Binding mode of the compound with the highest predicted binding affinity was visualized and superimposed with the receptor known inhibitor (Fig. 2). All compounds were found to occupy the active site of the protein. (-)-Epigallocatechin-3gallate resembled similar binding mode with gefitinib, whereas its core structure aligned with the quinazoline and aniline moiety. While genistein-4'O-glucuronide, (-)-epicatechin-3-gallate, quercetin3'-glucuronide only shared small geometrical similarity when compared with the bound ligand. Furthermore, hydrogen bond inferred by Pose View was compared and presented in (Table 2). Similar to gefitinib, (-)-epigallocatechin-3-gallate formed hydrogen bond with Met793. SYR127063 and genistein-4'-O-glucuronide shared no similar intermolecular interaction. Quercetin-3'-glucuronide had similar interaction with 4-hydroxytamoxifen at Glu353. (-)-Epicatechin-3-gallate had the most hydrogen bond towards ESR1.

\section{DISCUSSION}

In present study, predicted binding affinity and binding mode of conjugated flavonoids present in plasma after ingestion of dietary flavonoids against ER, EGFR kinase domain, and HER2 kinase domain were characterized in silico. The result shows that most compounds with predicted high binding affinity were glucuronide flavonoid conjugates. It is interesting to point out that the predominant flavonoid metabolite found in plasma after an hour ingestion of radiolabelled epicatechin was its glucuronide conjugates $^{29}$. Thus, the potential compounds found in this study were likely exist in large concentration in plasma after consumption of dietary flavonoids.

More than $70 \%$ diagnosed breast cancer was the overexpressed $\mathrm{ER}^{3}$. ER plays important role in development and progression of breast cancer, since ER drives proliferation of mammary cells upon binding with estrogenic hormone ${ }^{30} . \mathrm{ER}^{+}$breast cancer is sensitive against endocrine therapy and is effectively treated using selective estrogen receptor modulators such as tamoxifen ${ }^{31}$. This study found that (-)-epicatechin-3-gallate was a potential inhibitor of ER, because of its high predicted binding affinity and similar binding mode when compared to active metabolite of tamoxifen (4hydroxytamoxifen). Tamoxifen interacts with several amino acid residues inside the binding pocket, including Leu346, Thr347 and Leu387, forming a van der walls interaction that stabilize the com- 
plex $^{25}$. Epicatechin conjugates was predicted to be interacted with similar manner. This finding confirmed by other studies whereas epicatechin gallate was able to hamper ER activity through direct inhibition $^{32,33}$. Quercetin conjugates also have high predicted binding affinity towards ER. But quercetin conjugates may act as an agonist rather than antagonist, since previous study found that aglycone quercetin induced cell proliferation of ER-positive breast cancer cell line through ER stimulation ${ }^{34}$.

HER2 is a receptor tyrosine kinase which is overexpressed in $30 \%$ human breast cancer ${ }^{3}$. HER2 ${ }^{+}$ breast cancer characterized by its aggressive phenotype: high tumorigenicity and invaseness ${ }^{35}$. The treatment involved is either by targeting the extracellular domain using trastuzumab or its kinase domain using lapatinib ${ }^{4,36}$. Previous study showed that flavonoid compounds were able to inhibit human kinases ${ }^{37}$. Molecular docking study reported that genistein-4'-O-glucuronide had predicted binding affinity close to SYR127063. SYR127063 itself is a potent HER2 kinase domain inhibitor at IC50 of 11 $\mathrm{nM}^{26}$. From the experimental study, genistein was able to attenuate HER2 phosphorylation in BT474 cell line through tyrosine kinase inhibition, thus supported present finding ${ }^{38}$.

TNBC occurs approximately $10 \%$ in breast cancer cases3. TNBC is biologically aggressive and has the poorest prognosis when compared to other subtypes $^{3}$. Previous study reported that EGFR is a potential target for $\mathrm{TNBC}^{7}$. In this work, epigallocatechin and epicatechin metabolites had notable predicted binding affinity towards EGFR kinase domain. This finding supported by another study where epigallocatechin-3-gallate was able to inhibit EGFR activity ${ }^{39}$. Inhibition of EGFR by epigallocatechin conjugate may also affect HER2 activation, since both proteins are able to form heterodimeric complex and activate each other.

\section{CONCLUSION}

Binding affinity and binding mode between conjugated flavonoids found in plasma against ER, HER2, EGFR had been characterized in silico. Supported by other studies, conjugated flavonoids may exert similar inhibitory and agonistic properties to their parent flavonoids. Our study thus confirm and offer possible explanations how dietary flavonoids act against various breast cancer subtypes.

Acknowledgements: This research was funded by the Ministry of Research, Technology and Higher Education of the Republic of Indonesia and for research grant 2019
(Penelitian Dasar Unggulan Perguruan Tinggi). We are thankful to Hanna Sari W Kusuma, Ubaydillah Zedd Munshy, Ika Adhani Sholihah, Dwi Surya Artie, Dewani Tediana Yusepany, Rr. Anisa Siwianti, Riyani Lestari from Aretha Medika Utama Biomolecular and Biomedical Research Center, Bandung, Indonesia for their valuable assistance.

\section{REFERENCES}

1. Bray F, Ferlay J, Soerjomataram I, Siegel RL, Torre LA, Jemal A (2008) Global cancer statistics 2018: GLOBOCAN estimates of incidence and mortality worldwide for 36 cancers in 185 countries. CA Cancer $J$ Clin 68, 394-424.

2. Holliday DL, Speirs V (2011) Choosing the right cell line for breast cancer research. Breast Cancer Res 13, ID 215.

3. Hennigs A, Riedel F, Gondos A, Sinn P, Schirmacher P, Marmé F, Jäger D, Kauczor HU, et al (2016) Prognosis of breast cancer molecular subtypes in routine clinical care: A large prospective cohort study. BMC Cancer 16, ID 734.

4. Goldhirsch A, Winer EP, Coates AS, Gelber RD, Piccart-Gebhart M, Thürlimann B, Senn HJ, Panel members, et al (2013) Personalizing the treatment of women with early breast cancer: highlights of the st gallen international expert consensus on the primary therapy of early breast cancer. Ann Oncol 24, 2206-2223.

5. Hwang KT, Kim EK, Jung SH, Lee ES, Kim SI, Lee S, Park HK, Kim J, et al (2018) Tamoxifen therapy improves overall survival in luminal a subtype of ductal carcinoma in Situ: a study based on nationwide korean breast cancer registry database. Breast Cancer Res Treat 169, 11-22.

6. Goldhirsch A, Gelber RD, Piccart-Gebhart MJ, De Azambuja E, Procter M, Suter TM, Jackisch C, Cameron D, et al (2013) 2 years versus 1 year of adjuvant trastuzumab for HER2-positive breast cancer (HERA): An open-label, randomised controlled trial. Lancet 382, 1021-1028.

7. Savage P, Blanchet-Cohen A, Revil T, Badescu D, Saleh SM, Wang YC, Zuo D, Liu L, et al (2017) A targetable EGFR-dependent tumor-initiating program in breast cancer. Cell Rep 21, 1140-1149.

8. Chun OK, Chung SJ, Song WO (2007) Estimated dietary flavonoid intake and major food sources of U.S. adults. J Nutr 137, 1244-1252.

9. Lotito SB, Frei B (2006) Consumption of flavonoidrich foods and increased plasma antioxidant capacity in humans: cause, consequence, or epiphenomenon? Free Radic Biol Med 41, 1727-1746.

10. Hoensch HP, Oertel R (2015) The value of flavonoids for the human nutrition: short review and Perspectives. Clin Nutr Exp 3, 8-14. 
11. Tangney CC, Rasmussen HE (2013) Polyphenols, inflammation, and cardiovascular disease. Curr Atheroscler Rep 15, ID 324.

12. Hollman PCH, Geelen A, Kromhout D (2010) Dietary flavonol intake may lower stroke risk in men and women. J Nutr 140, 600-604.

13. González CA, Sala N, Rokkas T (2013) Gastric cancer: epidemiologic aspects. Helicobacter 18, 34-38.

14. Woo HD, Kim J (2013) Dietary flavonoid intake and smoking-related cancer risk: a meta-analysis. PLOS One 8, ID e75604.

15. Shrubsole MJ, Lu W, Chen Z, Shu XO, Zheng Y, Dai Q, Cai Q, Gu K, et al (2009) Drinking green tea modestly reduces breast cancer risk. $J$ Nutr 139, 310-316.

16. Wu AH, Yu MC, Tseng C-C, Hankin J, Pike MC (2003) Green tea and risk of breast cancer in asian americans. Int $J$ Cancer 106, 574-579.

17. Zhang M, Holman CDJ, Huang J-P, Xie X (2006) Green tea and the prevention of breast cancer: a case-control study in southeast china. Carcinogenesis 28, 1074-1078.

18. Iwasaki M, Inoue M, Sasazuki S, Sawada N, Yamaji T, Shimazu T, Willett WC, Tsugane S (2010) Green tea drinking and subsequent risk of breast cancer in a population to based cohort of Japanese women. Breast Cancer Res 12, ID R88.

19. Wu AH, Yu MC, Tseng C-C, Pike MC (2007) Body size, hormone therapy and risk of breast cancer in asianamerican women. Int $J$ Cancer 120, 844-852.

20. Day AJ, Canada FJ, Diaz JC, Kroon PA, Mclauchlan R, Faulds CB, Plumb GW, Morgan MR, et al (2000) Dietary flavonoid and isoflavone glycosides are hydrolysed by the lactase site of lactase phlorizin hydrolase. FEBS Lett 468, 166-170.

21. Crozier A, Del Rio D, Clifford MN (2010) Bioavailability of dietary flavonoids and phenolic compounds. Mol Aspects Med 31, 446-467.

22. Mullen W, Edwards CA, Crozier A (2006) Absorption, excretion and metabolite profiling of methyl, glucuronyl, glucosyl, and sulpho-conjugates of quercetin in human plasma and urine after ingestion of onions. Br J Nutr 96, ID 107.

23. Del Rio D, Calani L, Cordero C, Salvatore S, Pellegrini N, Brighenti F (2010) Bioavailability and catabolism of green tea flavan-3-ols in humans. Nutrition 26, 1110-1116.

24. Hosoda K, Furuta T, Yokokawa A, Ogura K, Hiratsuka A, Ishii K (2008) Plasma profiling of intact isoflavone metabolites by high-performance liquid chromatography and mass spectrometric identification of flavone glycosides daidzin and genistin in human plasma after administration of kinako. Drug Metab Dispos 36, 1485-1495.

25. Shiau AK, Barstad D, Loria PM, Cheng L, Kushner PJ, Agard DA, Greene GL (1998) The structural basis of estrogen receptor/coactivator recognition and the antagonism of this interaction by tamoxifen. Cell $\mathbf{9 5}$,
927-937.

26. Aertgeerts K, Skene R, Yano J, Sang BC, Zou H, Snell G, Jennings A, Iwamoto K et al (2011) Structural analysis of the mechanism of inhibition and allosteric activation of the kinase domain of HER2 protein. $J$ Biol Chem 286, 18756-18765.

27. Stierand K, Rarey M (2010) Drawing the PDB: proteinâĽšligand complexes in two dimensions. ACS Med Chem Lett 1, 540-545.

28. Yun CH, Boggon TJ, Li Y, Woo MS, Greulich H, Meyerson M, Eck MJ (2007) Structures of lung cancerderived EGFR mutants and inhibitor complexes: mechanism of activation and insights into differential inhibitor sensitivity. Cancer Cell 11, 217-227.

29. Ottaviani JI, Borges G, Momma TY, Spencer JP, Keen CL, Crozier A, Schroeter H (2016) The metabolome of [2-14C](ấL Š)-epicatechin in humans: implications for the assessment of efficacy, safety and mechanisms of action of polyphenolic bioactives. Sci Rep 6, ID 29034.

30. Sommer S, Fuqua SA (2001) Estrogen receptor and breast cancer. Semin Cancer Biol 11, 339-352.

31. Narod S, Nazarali S (2014) Tamoxifen for women at high risk of breast cancer. Breast Cancer Targets Ther 6. ID 29.

32. Kuruto-Niwa R, Inoue $S$, Ogawa S, Muramatsu M, Nozawa R (2000) Effects of tea catechins on the EREregulated estrogenic activity. J Agric Food Chem 48, 6355-6361.

33. Goodin MG (2002) Estrogen receptor-mediated actions of polyphenolic catechins in vivo and in vitro. Toxicol Sci 69, 354-361.

34. van der Woude $H$, ter Veld MG, Jacobs $N$, van der Saag PT, Murk AJ, Rietjens IM (2005) The stimulation of cell proliferation by quercetin is mediated by the estrogen receptor. Mol Nutr Food Res 49, 763-771.

35. Moasser MM (2007) The oncogene HER2: Its signaling and transforming functions and its role in human cancer pathogenesis. Oncogene 26, 6469-6487.

36. Schroeder R, Stevens C, Sridhar J (2014) Small molecule tyrosine kinase inhibitors of ErbB2/HER2/Neu in the treatment of aggressive breast cancer. Molecules 19, 15196-15212.

37. Williams RJ, Spencer JP, Rice-Evans C (2004) Flavonoids: antioxidants or signalling molecules? Free Radic Biol Med 36, 838-849.

38. Sakla MS, Shenouda NS, Ansell PJ, MacDonald RS, Lubahn DB (2007) Genistein affects HER2 protein concentration, activation, and promoter regulation in BT-474 human breast cancer cells. Endocrine 32, 69-78.

39. Masuda M, Suzui M, Lim JTE, Weinstein IB (2003) Epigallocatechin-3-gallate inhibits activation of HER$2 /$ neu and downstream signaling pathways in human head and neck and breast carcinoma cells. Clin Cancer Res 9, 3486-3491. 